\title{
Persepsi dan Perilaku Mahasiswa Keperawatan tentang Integritas Akademik
}

\author{
Lisa Musharyanti ${ }^{1}$, Gandes Retno Rahayu ${ }^{2}$, Yayi Suryo Prabandari ${ }^{2}$ \\ ${ }^{1}$ Program Studi IImu Keperawatan, Fakultas Kedokteran dan IImu Kesehatan Universitas Muhammadiyah \\ Yogyakarta \\ ${ }^{2}$ Fakultas Kedokteran Universitas Gadjah Mada, Yogyakarta
}

\begin{abstract}
Background: Besides knowledge and clinical skills, nursing students should have professional behavior as an essential component of competences as a side of knowledge and clinical skills. One aspect of professionalism is academic integrity. Lecturer should know about students' perception of academic integrity and behavior, to make a good way to detect and prevent the deviant behavior.

Objective: To describe nursing students' perception and behavior on academic integrity.

Method: Survey was conducted in a nursing school in Yogyakarta. The subject were 230 nursing students who were taken by proportionate stratified random sampling. The data were analyzed with descriptive analysis.

Result: There were many deviant or unacceptable behaviors which were not considered as an academic misconduct (by 5.2\%-61.3\% students). Peer students' percentage who had done an academic misconduct with 10 of the highest percentage was $50 \%-82.2 \%$ and the behavior ever done by students was $28.7 \%-68.7 \%$. The intention to do the behavior in the future was $3-38.7 \%$.

Conclusion: Perceptions of nursing students on academic integrity varied widely. Many of the actual behaviors were not considered as academic misconduct. Nursing students had different opinions about the behavior that violated academic integrity. Students'perceptions about the behavior and the behavior of a peer friend were in accordance with the students' own behavior. Therefore, there is a need for a shared perception between institutions and students about behaviors that violate academic integrity.
\end{abstract}

Keywords: professional behavior, academic integrity, academic dishonesty, perception, behavior

\begin{abstract}
Abstrak
Latar Belakang: Perilaku profesional merupakan salah satu unsur yang harus dimiliki oleh mahasiswa keperawatan selain pengetahuan dan keterampilan klinik, agar menjadi perawat professional ketika telah terjun di dunia kerja. Salah satu aspek yang mencerminkan perilaku professional pada mahasiswa yaitu integritas akademik yang dimiliki oleh mahasiswa, baik persepsi mahasiswa tentang perilaku apa saja yang dianggap benar atau salah karena hal ini akan memperilaku perilaku mereka selama proses pendidikan.

Tujuan: Penelitian ini dilakukan untuk mengetahui persepsi dan perilaku mahasiswa keperawatan tentang integritas akademik.

Metode: Penelitian ini menggunakan metode deskriptif kuantitatif dengan pendekatan survey. Subjek penelitian adalah 230 mahasiswa keperawatan yang diambil secara proporsional stratifikasi random sampling, dari tahun pertama sampai tahun terakhir baik mahasiswa S1 maupun profesi. Data dianalisis dengan analisis deskriptif.

Hasil: Banyak perilaku yang sebenarnya melanggar integritas akademik namun dianggap tidak melanggar (oleh 5,2\%-61,3\% mahasiswa). Persentase teman mahasiswa yang pernah melakukan pelanggaran integritas akademik dengan 10 persentase tertinggi sebanyak 50-82,2\% dan perilaku tidak profesional yang dilakukan mahasiswa 28,7$68,7 \%$. Persentase perilaku yang akan dilakukan 3-38,7\%. Mahasiswa memilih level sanksi "peringatan lisan" untuk 22 butir perilaku.
\end{abstract}

Korespondensi: riyanti25@yahoo.com; Telp.085729015245 
Kesimpulan: Mahasiswa keperawatan mempunyai persepsi yan bervariasi tentang perilaku yang melanggar integritas akademik. Persepsi mahasiswa tentang perilaku tersebut serta perilaku teman sesuai dengan perilaku mahasiswa itu sendiri dan perilakunya di masa yang akan datang. Banyak mahasiswa yang memilih level sanksi yang ringan untuk banyak pelanggaran integritas akademik.

Kata Kunci: perilaku profesional, academic integrity, academic dishonesty, persepsi, perilaku.

\section{PENDAHULUAN}

Profesionalisme tenaga kesehatan termasuk perawat, sangat ditekankan dalam dunia kerja. Salah satu komponen yang mempengaruhi perilaku profesional tersebut adalah integritas akademik yang dimiliki mahasiswa sejak proses pendidikan di perguruan tinggi. Banyak penelitian menyatakan bahwa perilaku academic dishonesty seperti cheating, plagiarisme, dan lainnya masih menjadi masalah di pendidikan tinggi seiring dengan peningkatan kemajuan teknologi informasi. ${ }^{1,2,3}$ Survey yang pernah dilakukan di Indonesia juga menunjukkan bahwa 70\% responden pernah melakukan kecurangan baik di sekolah menengah atas maupun di perguruan tinggi. ${ }^{4}$ Sedangkan menurut Brown, yang disitasi oleh Harper, yang melakukan survey pada 253 mahasiswa keperawatan menemukan bahwa 61\%-94\% mahasiswa pernah melihat rekannya melakukan cheating dan $8 \%$ $39 \%$ pernah melakukannya sendiri. Hal ini menunjukkan bahwa masalah integritas akademik menjadi masalah serius di dunia pendidikan, dalam hal ini khususnya pendidikan keperawatan, padahal profesi kesehatan menuntut adanya kejujuran, sikap etis dan moral yang tinggi. $5,6,7$

Dalam konteks profesi keperawatan, profesionalisme juga ditekankan dengan adanya kode etik profesi baik di tingkat nasional maupun internasional. International Council of Nurses (ICN) telah merumuskan The ICN Code of Ethics for Nurses (2005) yang di dalamnya memuat empat elemen kode etik perawat. ${ }^{8}$ Demikian juga American Nurses Association (ANA) telah menetapkan standar etika keperawatan, di dalamnya tidak hanya mensyaratkan kompetensi yang memadai, namun juga mencakup nilai-nilai tanggungjawab, akuntabilitas, dan respek kepada pasien dalam memberikan asuhan keperawatan. ${ }^{9}$ Demikian juga di Indonesia, Asosiasi Institusi Pendidikan Ners Indonesia (2008) juga menetapkan elemen professional behavior sebagai salah satu kompetensi lulusan ners. ${ }^{10}$

Beberapa isu penting dalam professional behavior khususnya integritas akademik, antara lain; apakah mahasiswa telah mengetahui perilaku yang melanggar integritas akademik, apakah mahasiswa melakukan pelanggaran integritas akademik, dan bagaimana persepsi mahasiswa mengenai sanksi yang perlu diberikan bagi mahasiswa yang melanggar integritas akademik. Persepsi adalah penafsiran yang unik dari seseorang terhadap sesuatu. Sedangkan perilaku adalah suatu fungsi dari interaksi individu dengan lingkungannya. ${ }^{11}$ Kedua hal ini, terkait dengan masalah integritas akademik, perlu diketahui sebagai data base bagi dosen dan institusi untuk dapat menyamakan persepsi dengan mahasiswa tentang integritas akademik yang harus dipatuhi dan menanamkan nilai-nilai integritas akademik serta profesionalisme kepada mahasiswa.

Dari uraian tersebut dapat disimpulkan bahwa professional behavior merupakan hal yang penting dalam dunia keperawatan baik di tingkat internasional, nasional, dan institusional, maka professional behavior harus dimiliki mahasiswa dan lulusan keperawatan. Integritas akademik yang merupakan unsur dari professional behavior harus ditanamkan sejak dini, maka kita perlu mengetahui apakah mahasiswa keperawatan telah mengetahui tentang professional behavior khususnya integritas akademik dan apakah mahasiswa keperawatan telah mengimplementasikannya dalam kehidupan akademik sebagai prediktor profesionalism enya di dunia kerja.

\section{TUIUAN}

Penelitian ini bertujuan untuk mengetahui: (1) persepsi mahasiswa keperawatan tentang perilaku apa saja yang dianggap melanggar integritas akademik dan yang dianggap tidak melanggar, (2) perilaku mahasiswa 
keperawatan tentang integritas akademik, (3) persepsi mahasiswa keperawatan tentang level sanksi yang diberikan pada pelanggaran integritas akademik yang dilakukan pertama kali.

\section{METODE}

Metode penelitian ini adalah deskriptif kuantitatif. Subjek penelitian adalah semua mahasiswa di sebuah program studi keperawatan di Yogyakarta, dari tahun pertama hingga tahun terakhir pada saat penelitian dilakukan. Peneliti mengambil sampel sebanyak 230 orang, mencakup mahasiswa S1 maupun mahasiswa profesi. Penentuan jumlah pemilihan subyek dilakukan dengan proportionate stratified random sampling agar mendapatkan jumlah yang proporsional dari setiap tahun angkatan. Cara pengumpulan data dengan kuesioner yang dikembangkan oleh Roff (2009). Kuesioner telah dilakukan uji validitas reliabilitas sehingga dari jumlah awal 41 butir tersisa 32 butir yang dilakukan analisis.

Analisis data deskriptif digunakan untuk mengetahui persentase tentang persepsi mahasiswa mengenai integritas akademik dengan membuat cross tabulation dengan karakteristik responden. Demikian juga data tentang perilaku integritas akademik baik perilaku aktual maupun yang akan datang serta persepsi mengenai level sanksi yang dipilih oleh responden.

\section{HASIL}

\section{Karakteristik Umum Responden}

Pada penelitian ini, responden perempuan adalah mayoritas yaitu $84,3 \%$ dari semua responden yang terlibat dalam penelitian.

Tabel 1. Distribusi responden berdasarkan jenis kelamin, umur, dan tahun angkatan

\begin{tabular}{cccc} 
& $\begin{array}{c}\text { Program A } \\
\text { (n) }\end{array}$ & $\begin{array}{c}\text { Program B } \\
\text { (n) }\end{array}$ & Jumlah \\
1. Jenis Kelamin & 18 & 18 & 36 \\
Laki-laki & 150 & 44 & 194 \\
Pcrcmpuan & & & \\
2. Umur & 84 & 1 & 85 \\
$<20$ tahun & 84 & 26 & 110 \\
21 - 25 tahun & 0 & 13 & 13 \\
26-30 tahun & 0 & 22 & 22 \\
$>30$ tahun & & & \\
3. Kelompok Angkatan & 45 & - & 182 \\
S1 2009 & 35 & - & \\
2008 & 35 & 25 & 48 \\
2007 & 30 & & \\
2006 & 23 & & \\
Profesi & & & \\
\hline
\end{tabular}

Persepsi Mahasiswa Tentang Integritas Akademik

Pendapat mahasiswa tentang perilaku yang melanggar integritas akademik

Dari 32 butir yang menggambarkan perilaku integritas akademik, mahasiswa diminta menjawab pertanyaan "Apakah ini salah?" dengan pilihan "ya”, "tidak yakin”, dan "tidak". Disamping perilaku yang dianggap melanggar, yang menarik adalah cukup banyak perilaku dianggap tidak melanggar oleh sebagian mahasiswa. Berikut 10 perilaku yang memiliki persentase terbesar yang dianggap tidak melanggar oleh mahasiswa keperawatan. 
Tabel 2. Sepuluh perilaku yang termasuk 10 persentase tertinggi dianggap tidak melanggar oleh mahasiswa keperawatan $(\mathrm{N}=230)$

\begin{tabular}{|c|c|c|c|c|}
\hline \multirow[t]{2}{*}{$\begin{array}{l}\text { No } \\
\text { butir }\end{array}$} & \multirow[t]{2}{*}{$\begin{array}{c}\text { Isi } \\
\text { butir }\end{array}$} & \multicolumn{3}{|c|}{$\begin{array}{l}\text { Apakah ini salah? } \\
\text { (dalam \%) }\end{array}$} \\
\hline & & Ya & Tidak yakin & Tidak \\
\hline 27 & Mengubah ranking dalam lembar data resmi & 99,6 & 0,0 & 0,4 \\
\hline 22 & $\begin{array}{l}\text { Sengaja memalsukan hasil tes atau rekaman tindakan (pasien) } \\
\text { untuk menyembunyikan kesalahannya }\end{array}$ & 99,1 & 0,4 & 0,4 \\
\hline 32 & $\begin{array}{l}\text { Merusak barang milik umum seperti mencoret-coret meja } \\
\text { atau kursi }\end{array}$ & 99,1 & 0,4 & 0,4 \\
\hline 28 & $\begin{array}{l}\text { Mengancam atau melecehkan secara verbal pegawai universitas } \\
\text { atau teman mahasiswa }\end{array}$ & 98,7 & 0,9 & 0,4 \\
\hline 19 & $\begin{array}{l}\text { Mengatur cara agar lulus dari ujian dengan menggunakan } \\
\text { koneksi pribadi atau dengan cara suap }\end{array}$ & 98,3 & 1,3 & 0,4 \\
\hline 23 & $\begin{array}{l}\text { Tidak mematuhi prosedur kontrol infeksi secara benar } \\
\text { (di rumah sakit ketika praktik) }\end{array}$ & 98,3 & 0,4 & 0,9 \\
\hline 25 & $\begin{array}{l}\text { Mcmalsukan tanda tangan pctugas kcschatan pada hasil kcrja, } \\
\text { grafik pasien, lembar ranking, atau lembar kedatangan }\end{array}$ & 98,3 & 1,3 & 0,4 \\
\hline 26 & $\begin{array}{l}\text { Mcmalsukan referensi atau ranking/grade pada curriculum } \\
\text { vitae (misalnya saat melamar pekerjaan) }\end{array}$ & 98,3 & 0,0 & 1,7 \\
\hline 29 & $\begin{array}{l}\text { Terlibat aktivitas pedofilia (memiliki atau melihat foto-foto } \\
\text { pornografi anak) }\end{array}$ & 98,3 & 1,3 & 0,4 \\
\hline 15 & $\begin{array}{l}\text { Saling tukar jawaban dengan menggunakan media hand- } \\
\text { phone selama ujian }\end{array}$ & 97,8 & 1,3 & 0,9 \\
\hline 12 & Mensabotase pekerjaan mahasiswa lain & 97,4 & 1,3 & 1,3 \\
\hline 13 & $\begin{array}{l}\text { Menggunakan kedekatan pribadi, suap, atau ancaman untuk } \\
\text { mendapatkan keuntungan akademis (misal menaikkan nilai } \\
\text { ujian) }\end{array}$ & 97,4 & 0,9 & 1,7 \\
\hline 17 & $\begin{array}{l}\text { Membawa materi yang dilarang saat ujian (contoh; } \\
\text { lembar contekan) }\end{array}$ & 97,4 & 1,7 & 0,9 \\
\hline
\end{tabular}

Dari Tabel 2 tampak bahwa "membantu teman mahasiswa menyelesaikan tugas" dipilih oleh mahasiswa sebagai perilaku yang dianggap tidak melanggar dengan persentase terbanyak. Yang juga menarik adalah mahasiswa yang ragu-ragu apakah butir tersebut salah atau tidak, persentase mahasiswa yang ragu-ragu cukup tinggi yaitu diatas sepuluh persen pada 9 butir. Perilaku yang dianggap melanggar dapat dilihat pada Tabel 3. 
Tabel 3. Butir yang termasuk 10 persentase tertinggi dianggap melanggar oleh mahasiswa keperawatan $(\mathrm{N}=230)$

\begin{tabular}{|c|c|c|c|c|}
\hline \multirow[t]{2}{*}{$\begin{array}{l}\text { No } \\
\text { butir }\end{array}$} & \multirow[t]{2}{*}{$\begin{array}{c}\text { Isi } \\
\text { butir }\end{array}$} & \multicolumn{3}{|c|}{$\begin{array}{l}\text { Apakah ini salah? } \\
(\text { dalam \%) }\end{array}$} \\
\hline & & Ya & Tidak yakin & Tidak \\
\hline 2 & Membantu teman mahasiswa menyelesaikan tugas & 18,7 & 20,0 & 61,3 \\
\hline 10 & $\begin{array}{l}\text { Mengakses makalah atau tugas kuliah yang lama, yang tidak } \\
\text { dipublikasikan untuk seluruh kelas, untuk membantu studi }\end{array}$ & 34,8 & 25,2 & 40,0 \\
\hline 16 & $\begin{array}{l}\text { Menerima informasi dari teman mahasiswa mengenai maka- } \\
\text { lah atau tugas kuliah yang telah diujikan, atau menyediakan } \\
\text { informasi mengenai sebuah karya tulis/makalah untuk te- } \\
\text { man mahasiswa yang belum ujian }\end{array}$ & 50,0 & 21,7 & 28,3 \\
\hline 8 & $\begin{array}{l}\text { Mengutip sebuah sumber yang pada kenyataannya tidak di- } \\
\text { baca seluruhnya }\end{array}$ & 45,7 & 34,8 & 19,6 \\
\hline 3 & $\begin{array}{l}\text { Mcndapatkan atau membcrikan bantuan untuk tugas } \\
\text { kuliah, menyalahi aturan pengajar (contoh: meminjamkan } \\
\text { pekerjaannya pada mahasiswa lain) }\end{array}$ & 66,1 & 16,1 & 17,8 \\
\hline 5 & $\begin{array}{l}\text { Mengumpulkan tugas yang pernah dikumpulkan sebelum- } \\
\text { nya untuk tugas lainnya atau tugas pada perkuliahan lain }\end{array}$ & 64,3 & 19,6 & 16,1 \\
\hline 24 & $\begin{array}{l}\text { Memeriksa pasien tanpa sepengetahuan atau persetujuan } \\
\text { penyelia yang mengawasi }\end{array}$ & 63,0 & 21,7 & 15,2 \\
\hline 7 & $\begin{array}{l}\text { Tidak mengutip secara benar sumber informasi (contoh: } \\
\text { mengkopi sebuah teks secara langsung tetapi hanya meng- } \\
\text { ikutkan sumber dalam daftar referensi) }\end{array}$ & 65,7 & 22,6 & 11,7 \\
\hline 4 & Mengklaim hasil kerja kelompok sebagai kerja individu & 92,6 & 1,7 & 5,7 \\
\hline 30 & Sering terlambat hadir di kelas & 81,3 & 13,5 & 5,2 \\
\hline
\end{tabular}

Pada perilaku yang dianggap melanggar oleh mayoritas mahasiswa, terlihat bahwa beberapa mahasiswa dalam persentase yang kecil masuk dalam golongan yang tidak yakin dan golongan yang menganggap perilaku tidak melanggar.

\section{Perilaku mahasiswa keperawatan tentang integritas akademik}

Penelitian ini meneliti perilaku mahasiswa dari 3 aspek, yaitu perilaku teman, perilaku mahasiswa (responden) yang pernah dilakukan dan yang akan dilakukan. Gambaran perilaku teman mahasiswa dengan pertanyaan "apakah teman Anda sesama mahasiswa melakukan hal ini?" didapatkan 10 persentase terbesar untuk jawaban "ya" seperti pada Tabel 4. 
Tabel 4. Butir yang termasuk 10 persentase tertinggi dilakukan oleh teman mahasiswa $(\mathrm{N}=230)$

\begin{tabular}{|c|c|c|c|c|}
\hline \multirow[t]{2}{*}{$\begin{array}{l}\text { No } \\
\text { butir }\end{array}$} & \multirow[t]{2}{*}{$\begin{array}{c}\text { Isi } \\
\text { butir }\end{array}$} & \multicolumn{3}{|c|}{$\begin{array}{l}\text { Apakah ini salah? } \\
\quad(\text { dalam } \%)\end{array}$} \\
\hline & & Ya & Tidak yakin & Tidak \\
\hline 2 & Membantu teman mahasiswa menyelesaikan tugas & 4,8 & 13,0 & 82,2 \\
\hline 20 & $\begin{array}{l}\text { Menandatangani daftar hadir untuk teman yang absen, atau } \\
\text { meminta tcman sckclas untuk menandatangani daftar hadir } \\
\text { untuk Anda di laboratorium atau perkuliahan }\end{array}$ & 7,0 & 14,3 & 78,7 \\
\hline 30 & Sering terlambat hadir di kelas & 13,9 & 14,3 & 71,7 \\
\hline 14 & $\begin{array}{l}\text { Mencontek jawaban dari teman sebelah atau memungkin- } \\
\text { kan teman sebelah Anda untuk mencontek jawaban Anda } \\
\text { selama ujian }\end{array}$ & 12,2 & 27,4 & 60,4 \\
\hline 21 & Sering tidak hadir pada perkuliahan & 18,7 & 22,2 & 59,1 \\
\hline 8 & $\begin{array}{l}\text { Mengutip sebuah sumber yang pada kenyataannya tidak dibaca } \\
\text { seluruhnya }\end{array}$ & 9,6 & 33,5 & 57,0 \\
\hline 31 & $\begin{array}{l}\text { Tidak mengerjakan bagian tugasnya, yang sudah dibagi oleh } \\
\text { kelompoknya }\end{array}$ & 25,2 & 18,7 & 56,1 \\
\hline 3 & $\begin{array}{l}\text { Mendapatkan atau memberikan bantuan untuk tugas kuliah, } \\
\text { menyalahi aturan pengajar (contoh: meminjamkan pekerjaan- } \\
\text { nya pada mahasiswa lain) }\end{array}$ & 16,5 & 27,8 & 55,7 \\
\hline 6 & $\begin{array}{l}\text { Dengan sengaja memparafrase sebuah teks pada sebuah tugas, } \\
\text { atau mengopi scbuah tcks sccara langsung tanpa mengutip } \\
\text { sumbcrnya }\end{array}$ & 16,5 & 33,0 & 50,4 \\
\hline 7 & $\begin{array}{l}\text { Tidak mengutip secara benar sumber informasi (contoh: } \\
\text { mengkopi sebuah teks secara langsung tetapi hanya mengikut- } \\
\text { kan sumber dalam daftar referensi) }\end{array}$ & 15,2 & 34,8 & 50,0 \\
\hline
\end{tabular}

Perilaku yang dilaporkan paling banyak dilakukan oleh teman mahasiswa adalah poin 2 yaitu "membantu teman mahasiswa menyelesaikan tugas" $(82,2 \%)$ dan yang paling banyak melaporkan hal itu adalah mahasiswa profesi program A (91,6\%). Dari segi umur, yang paling banyak temannya melakukan adalah umur $>30$ tahun (90,9\%). Sedangkan urutan kedua terbanyak adalah perilaku ke20 "menandatangani daftar hadir untuk teman yang absen, atau meminta teman sekelas menandatangani daftar hadir untuk Anda di laboratorium atau perkuliahan" sebanyak 78,7\% dari total responden melakukannya. Mahasiswa angkatan 2006 melaporkan temannya paling banyak melakukan $(96,7 \%)$.

Pertanyaan berikutnya yaitu "apakah Anda pernah melakukan hal ini?" dapat dilihat pada Tabel 5. 
Tabel 5. Perilaku akademik yang termasuk 10 persentase tertinggi pernah dilakukan oleh mahasiswa keperawatan $(\mathrm{N}=230)$

\begin{tabular}{|c|c|c|c|c|}
\hline \multirow[t]{2}{*}{$\begin{array}{l}\text { No } \\
\text { butir }\end{array}$} & \multirow[t]{2}{*}{$\begin{array}{l}\text { Isi } \\
\text { butir }\end{array}$} & \multicolumn{3}{|c|}{$\begin{array}{l}\text { Apakah ini salah? } \\
(\text { dalam \%) }\end{array}$} \\
\hline & & Ya & Tidak yakin & Tidak \\
\hline 2 & Membantu teman mahasiswa menyelesaikan tugas & 23,0 & 8,3 & 68,7 \\
\hline 20 & $\begin{array}{l}\text { Menandatangani daftar hadir untuk teman yang absen, atau } \\
\text { meminta teman sekelas untuk menandatangani daftar hadir } \\
\text { untuk Anda di lab. atau perkuliahan }\end{array}$ & 30,4 & 5,2 & 64,3 \\
\hline 8 & $\begin{array}{l}\text { Mengutip sebuah sumber yang pada kenyataannya tidak di- } \\
\text { baca seluruhnya }\end{array}$ & 26,1 & 16,1 & 57,8 \\
\hline 30 & Sering terlambat hadir di kelas & 37,8 & 9,6 & 52,6 \\
\hline 3 & $\begin{array}{l}\text { Mendapatkan atau memberikan bantuan untuk tugas kuliah, } \\
\text { menyalahi aturan pengajar (contoh: meminjamkan pekerjaan- } \\
\text { nya pada mahasiswa lain) }\end{array}$ & 41,7 & 9,1 & 49,1 \\
\hline 7 & $\begin{array}{l}\text { Tidak mengutip secara benar sumber informasi (contoh: meng- } \\
\text { kopi sebuah teks secara langsung tetapi hanya mengikutkan } \\
\text { sumber dalam daftar referensi) }\end{array}$ & 34,8 & 17,4 & 47,8 \\
\hline 6 & $\begin{array}{l}\text { Dengan sengaja memparafrase sebuah teks pada sebuah tugas, } \\
\text { atau mengopi sebuah teks secara langsung tanpa mengutip } \\
\text { sumbernya }\end{array}$ & 38,7 & 15,2 & 46,1 \\
\hline 14 & $\begin{array}{l}\text { Mencontek jawaban dari teman sebelah atau memungkinkan } \\
\text { teman sebelah Anda untuk mencontek jawaban Anda selama } \\
\text { ujian }\end{array}$ & 56,1 & 4,3 & 39,6 \\
\hline 10 & $\begin{array}{l}\text { Mengakses paper (makalah) atau tugas kuliah yang lama, yang } \\
\text { tidak dipublikasikan untuk seluruh kelas, untuk membantu } \\
\text { studi }\end{array}$ & 47,4 & 19,6 & 33,0 \\
\hline 16 & $\begin{array}{l}\text { Menerima informasi dari teman mahasiswa mengenai paper } \\
\text { yang telah diujikan, atau menyediakan informasi mengenai } \\
\text { sebuah karya tulis/paper untuk teman mahasiswa yang belum } \\
\text { ujian }\end{array}$ & 61,3 & 10,0 & 28,7 \\
\hline
\end{tabular}

Kelompok mahasiswa yang paling banyak melakukan bervariasi dari angkatan yang berbeda. Untuk butir 2 "membantu teman mahasiswa menyelesaikan tugas" yang terbanyak pernah melakukan adalah angkatan 2006 (86,7\%), sedang yang paling sedikit adalah angkatan 2008 (45,7\%). Butir 20 "menandatangani daftar hadir untuk teman yang absen, atau meminta teman sekelas untuk menandatangani daftar hadir untuk Anda di lab atau perkuliahan” yang terbanyak melakukan juga angkatan 2006 (93,3\%) dan yang paling sedikit adalah angkatan 2009 (42,2\%). Sedangkan perilaku 30 "sering terlambat hadir di kelas" dilakukan oleh mahasiswa profesi program A dan sebaliknya yang mengakui paling sedikit adalah mahasiswa profesi program B.

Aspek ke-3 dari perilaku mahasiswa yaitu pertanyaan “apakah Anda akan melakukan hal ini?" didapatkan gambaran jawaban responden pada Tabel 6 . 
Tabel 6. Perilaku yang termasuk 10 persentase tertinggi akan dilakukan oleh mahasiswa keperawatan $(\mathrm{N}=230)$

\begin{tabular}{|c|c|c|c|c|}
\hline \multirow[t]{2}{*}{$\begin{array}{l}\text { No } \\
\text { butir }\end{array}$} & \multirow[t]{2}{*}{$\begin{array}{l}\text { Isi } \\
\text { butir }\end{array}$} & \multicolumn{3}{|c|}{$\begin{array}{l}\text { Apakah ini salah? } \\
(\text { dalam \%) }\end{array}$} \\
\hline & & Ya & Tidak yakin & Tidak \\
\hline 2 & Membantu teman mahasiswa menyelesaikan tugas & 20,0 & 41,3 & 38,7 \\
\hline 16 & $\begin{array}{l}\text { Menerima informasi dari teman mahasiswa mengenai paper } \\
\text { yang telah diujikan, atau menyediakan informasi mengenai } \\
\text { sebuah karya tulis/paper untuk teman mahasiswa yang belum } \\
\text { ujian }\end{array}$ & 53,0 & 32,2 & 14,8 \\
\hline 10 & $\begin{array}{l}\text { Mengakses paper (makalah) atau tugas kuliah yang lama, yang } \\
\text { tidak dipublikasikan untuk seluruh kelas, untuk membantu } \\
\text { studi }\end{array}$ & 48,3 & 38,3 & 13,5 \\
\hline 3 & $\begin{array}{l}\text { Mendapatkan atau memberikan bantuan untuk tugas kuliah, } \\
\text { menyalahi aturan pengajar (contoh: meminjamkan pekerjaan- } \\
\text { nya pada mahasiswa lain) }\end{array}$ & 52,6 & 39,1 & 8,3 \\
\hline 8 & $\begin{array}{l}\text { Mengutip sebuah sumber yang pada kenyataannya tidak di- } \\
\text { baca seluruhnya }\end{array}$ & 50,9 & 41,3 & 7,8 \\
\hline 20 & $\begin{array}{l}\text { Menandatangani daftar hadir untuk teman yang absen, atau } \\
\text { meminta teman sekelas untuk menandatangani daftar hadir } \\
\text { untuk Anda di lab. atau perkuliahan }\end{array}$ & & 39,1 & 7,8 \\
\hline 23 & $\begin{array}{l}\text { Tidak mengikuti prosedur kontrol infeksi secara benar (di } \\
\text { rumah sakit ketika praktik) }\end{array}$ & 85,7 & 13,5 & 5,7 \\
\hline 7 & $\begin{array}{l}\text { Tidak mengutip sccara benar sumber informasi (contoh: } \\
\text { mengkopi sebuah teks secara langsung tetapi hanya meng- } \\
\text { ikutkan sumber dalam daftar referensi) }\end{array}$ & 59,6 & 35,2 & 5,2 \\
\hline 6 & $\begin{array}{l}\text { Dengan sengaja memparafrase sebuah teks pada sebuah tugas, } \\
\text { atau mengopi sebuah teks secara langsung tanpa mengutip } \\
\text { sumbernya }\end{array}$ & 68,3 & 27,8 & 3,9 \\
\hline 21 & Sering tidak hadir pada perkuliahan & 81,7 & 14,8 & 3,5 \\
\hline 30 & Sering terlambat hadir di kelas & 65,7 & 31,3 & 3,0 \\
\hline
\end{tabular}

Kelompok mahasiswa yang paling banyak akan melakukan bervariasi dari angkatan yang berbeda. Untuk perilaku nomor 2, yang terbanyak akan melakukan adalah mahasiswa profesi program B (70,8\%), sedang yang paling sedikit adalah angkatan 2008 dan 2007 (masing-masing 25,7\%). Perilaku nomor 16 yang terbanyak melakukan juga angkatan 2006 (93,3\%) dan yang paling sedikit adalah angkatan 2009 (42,2\%). Sedangkan perilaku nomor 10 paling tinggi persentasenya dilakukan oleh mahasiswa profesi program A dan sebaliknya yang mengakui paling sedikit adalah mahasiswa profesi program B. Secara keseluruhan ternyata perilaku no 2 "membantu teman mahasiswa menyelesaikan tugas" secara berurutan menempati persentase tertinggi dari keempat aspek yang ditanyakan. Tabel 7 menunjukkan rekapan dari keempat aspek pertanyaan di atas, sehingga dapat dilihat butir yang sama-sama memiliki persentase yang tinggi. 
Tabel 7. Tabel rekap dari empat aspek pertanyaan tentang integritas akademik yang termasuk 10 persentase tertinggi

\begin{tabular}{|c|c|c|c|c|}
\hline \multicolumn{2}{|c|}{$\begin{array}{l}\text { 1. Apakah ini salah? } \\
\text { (nomor butir } \\
\text { perilaku) }\end{array}$} & \multirow{2}{*}{$\begin{array}{l}\text { 2. Apakah teman } \\
\text { Anda pernah } \\
\text { melakukan ini? } \\
\text { (nomor butir } \\
\text { pcrilaku) } \\
\text { Ya }\end{array}$} & \multirow{2}{*}{$\begin{array}{l}\text { 3. Apakah Anda } \\
\text { pernah melaku- } \\
\text { kan ini? } \\
\text { (nomor butir } \\
\text { pcrilaku) } \\
\text { Ya }\end{array}$} & \multirow{2}{*}{$\begin{array}{l}\text { 4. Apakah Anda } \\
\text { akan melaku- } \\
\text { kan ini? } \\
\text { (nomor butir } \\
\text { perilaku) } \\
\text { Ya }\end{array}$} \\
\hline Ya & Tidak & & & \\
\hline 27 & 2 & 2 & 2 & 2 \\
\hline 22 & 10 & 20 & 20 & 16 \\
\hline 32 & 16 & 30 & 8 & 10 \\
\hline 28 & 8 & 14 & 30 & 3 \\
\hline 19 & 3 & 21 & 3 & 8 \\
\hline 23 & 5 & 8 & 7 & 20 \\
\hline 25 & 24 & 31 & 6 & 23 \\
\hline 26 & 7 & 3 & 14 & 7 \\
\hline 29 & 4 & 6 & 10 & 6 \\
\hline 15 & 30 & 7 & 16 & 21 \\
\hline 12 & & & & 30 \\
\hline \multicolumn{5}{|l|}{13} \\
\hline 17 & & & & \\
\hline
\end{tabular}

Keterangan tabel: nomor yang sama menunjukkan perilaku yang sama pada aspek pertanyaan yang berbeda

\section{PEMBAHASAN}

Persepsi dan perilaku adalah dua hal berkaitan, karena perilaku seseorang dipengaruhi oleh caranya dalam memandang sesuatu hal. ${ }^{12}$ Cara seseorang menilai suatu hal akan mempengaruhi perilakunya, apabila menganggap sesuatu itu benar maka akan melakukan, dan apabila menganggap hal tersebut salah maka akan menghindarinya. Dalam hal integritas akademik, misalnya kejujuran, persepsi mahasiswa mempengaruhi perilakunya. Walaupun tidak diukur secara statistik, nampak bahwa pada beberapa perilaku yang dianggap tidak melanggar oleh mahasiswa maka persentase yang melakukan jumlahnya cukup banyak. Hal ini sama dengan hasil penelitian yang lain bahwa pada mahasiswa yang menganggap bahwa perilaku tersebut tidak melanggar maka persentase mahasiswa yang melakukan cukup besar. ${ }^{13,14}$ Hal kedua yang menarik adalah 7 dari 10 besar perilaku yang memiliki persentase tertinggi adalah perilaku yang sejenis. Ini artinya bahwa perilaku yang persentasenya besar yang menganggap tidak 
melanggar di aspek "apakah hal ini salah?" maka butir itu juga masuk kategori 10 besar pada aspek lain: " apakah teman Anda melakukan hal ini?", "apakah Anda pernah melakukan hal ini?, dan "apakah Anda akan melakukan hal ini?". Oleh karena itu ada kecenderungan persepsi mahasiswa tentang suatu perilaku akan sesuai pula dengan perilakunya. Hal ini tampak jelas pada perilaku yang mempunyai persentase tertinggi untuk keempat aspek pertanyaan di atas, sehingga nampak bahwa "membantu teman mahasiswa menyelesaikan tugas" dianggap wajar, tidak melanggar, dan banyak yang melakukannya baik temannya maupun mahasiswa itu sendiri (lihat Tabel 8). Hal ini sama dengan penelitian oleh Media Group yang menemukan persentase yang sama tinggi antara perilaku teman dan perilaku responden penelitian. ${ }^{15}$ Menurut McCabe et.al, persepsi mahasiswa tentang perilaku teman sebaya merupakan salah satu faktor penting yang memicu mahasiswa melakukan suatu tindakan academic dishonesty. ${ }^{16}$ Beberapa penelitian menyatakan bahwa perilaku teman sebaya juga akan mempengaruhi persepsinya. ${ }^{15,16,17}$ Bila mahasiswa melihat temannya melakukan suatu tindakan, persepsinya mengatakan bahwa hal tersebut boleh dilakukan, selanjutnya ia sendiri pun akan melakukan hal yang sama. Mahasiwa juga dipengaruhi persepsinya dalam memandang akibat dari perilaku teman sebaya ketika melanggar integritas akademik, apakah temannya mendapat sanksi yang tegas atau tidak. Bila temannya tidak mendapat sanksi yang tegas dari institusi, maka hal ini memberi dorongan pada mahasiswa untuk melakukan hal yang sama karena merasa aman dari hukuman dan tidak memiliki resiko apapun.

Selanjutnya, persentase responden yang akan melakukan hanya 8 butir yang memiliki persentase nol "tidak akan melakukan" sementara 24 perilaku lain masih ada sebagian mahasiswa yang menjawab "akan melakukan". Selain itu golongan mahasiswa yang menjawab "tidak yakin" juga persentasenya cukup bervariasi dan hanya pada 2 butir persentasenya nol, artinya untuk 30 butir yang lain mahasiswa banyak yang tidak yakin atau raguragu apakah perilaku dalam kuesioner itu melanggar atau tidak. Kedua hal ini menarik karena menunjukkan dua hal: (1) mahasiswa tidak tahu betul perilaku apa saja yang melanggar dan yang tidak melanggar, (2) belum adanya kesepakatan yang jelas antara mahasiswa dan dosen atau institusi tentang perilaku apa yang melanggar integritas akademik dan yang tidak melanggar, sehingga mahasiswa hanya memutuskan menurut persepsinya masing-masing.

Rabi et al. menekankan pentingnya penjelasan dan sosialisasi oleh dosen dan institusi tentang integritas akademik sehingga mahasiswa dapat membentuk perilaku profesional sejak awal di institusi pendidikan, tidak hanya di akhir proses pendidikan $\mathrm{S} 1$ atau selama pendidikan profesi saja. ${ }^{18}$ Beberapa penelitian menunjukkan pentingnya mendiskusikan masalah profesionalisme kepada mahasiswa sejak mereka berada di tahun pertama, hal ini dikarenakan kurangnya profesionalisme di kalangan mahasiswa atau mahasiswa tidak memandang integritas akademik sebagai bagian dari perilaku profesional. ${ }^{13,17,18}$ Hammer et al. menambahkan perlu penjelasan yang spesifik kepada mahasiswa perilaku integritas apa saja yang diharapkan dan bagaimana mereka akan dievaluasi di dalam proses pendidikan. ${ }^{19}$

Terkait dengan profesi keperawatan, Asosiasi Institusi Pendidikan Ners Indonesia (AIPNI) telah menetapkan standar kompetensi lulusan ners yang di dalamnya telah dicantumkan aspek kepribadian, kerangka etik dan legal, sehingga integritas seorang perawat merupakan hal yang mutlak baik kejujuran, keadilan, tanggung jawab, dan respek. Demikian juga di tingkat internasional baik International Council of Nursing (ICN) maupun American Association of College of Nursing (AACN) telah menetapkan standar etika perawat. Menurut AACN, nilai professional perawat adalah integritas, altruisme, otonomi, human dignity, dan social justice. 9 American Nursing Association juga telah menyatakan bahwa standar etika perawat adalah kompetensi yang memadai, tanggung jawab, akuntabilitas, serta respek kepada pasien dalam memberikan asuhan keperawatan. ${ }^{20}$

Dalam visi misi program studi dan kompetensi lulusan di institusi tempat penelitian ini dilakukan, telah tercantum kualifikasi lulusan yang memiliki profesionalisme serta mampu menerapkan etik legal dalam praktik keperawatan, namun dalam buku panduan akademik untuk mahasiswa terlihat bahwa belum ada peraturan yang spesifik dan eksplisit tentang integritas akademik bagi mahasiswa yang dapat mencerminkan aspek 
perilaku yang sebenarnya diharapkan dari mahasiswa. Sedangkan di tingkat internasional yang telah mempunyai standar yang jelas tentang unsur-unsur perilaku profesional saja, prevalensi pelanggaran terhadap integritas ini masih tinggi, apalagi bila standar perilaku tersebut belum terdefinisikan secara eksplisit sehingga mudah dipahami oleh mahasiswa. Akan lebih sulit lagi bagi mahasiswa untuk melaksanakannya karena mereka sendiri tidak dipahamkan terlebih dahulu tentang apa saja unsur dari sikap profesional yang harus dimiliki mahasiswa. Padahal literatur telah menegaskan bahwa perilaku profesional perlu dijelaskan yang spesifik kepada mahasiswa, perilaku integritas apa saja yang diharapkan perlu disosialisasikan agar mahasiswa memahami dan melaksanakannya. ${ }^{13,17,18,19}$

Faktor lain yang mempengaruhi perilaku adalah penerapan sanksi bagi yang melanggar, kepastian akan dilaporkan atau dihukum bila melanggar, dan berat ringannya hukuman atau sanksi terhadap pelanggaran integritas akademik. ${ }^{15,18}$ Adakalanya institusi telah mempunyai aturan yang jelas mengenai hukuman bagi pelanggaran integritas akademik, namun civitas akademik belum memiliki kesepakatan yang sama untuk berlaku tegas dalam menerapkan peraturan tentang sanksi tersebut. Hal ini menyebabkan mahasiswa memandang ringan pada perilaku yang sebenarnya melanggar.

Dari uraian di atas tampak jelas bahwa persepsi benar salah dipengaruhi tidak adanya kesepakatan antara mahasiswa dan institusi tentang perilaku yang boleh atau tidak boleh dilakukan dalam hal integritas akademik. Selain itu perilaku teman sebaya yang melanggar dan tidak mendapat sanksi yang tegas mendorong mahasiswa melakukan hal yang sama, karena tidak takut akan akibat yang ditimbulkan dari perilaku tersebut.

\section{KESIMPULAN}

Persepsi mahasiswa keperawatan tentang perilaku integritas akademik bervariasi, masih banyak perilaku yang dianggap tidak melanggar dan dilakukan oleh mahasiswa maupun teman mahasiswa. Perilaku yang dianggap tidak melanggar, mempunyai kecenderungan dilakukan oleh banyak teman dan mahasiswa keperawatan.

\section{SARAN}

Perlu dibuat aturan tentang perilaku yang melanggar integritas akademik dan mencantumkannya di buku panduan akademik mahasiswa keperawatan. Perlu adanya ketegasan dalam pemberian sanksi bagi yang melanggar integritas akademik.

\section{DAFTAR PUSTAKA}

1. Bolin AU. Self control, perceived opportunity, and attitudes as predictors of academic dishonesty. The Journal of Psychology. 2004; 138(2):101-14.

2. Harding TS, Carpenter DD, Finelli CJ, Passow HJ. Does academic dishonesty relate to unethical behavior in professional practice? an exploratory study. Science and Enginering Ethics. 2004;10:311-24.

3. McCabe DL, Trevino LK. Individual and contextual influences on academic dishonesty, a multicampus investigation. Research in Higher Education. 1997;8(3): 379-96.

4. Harper MG. High tech cheating. Nurse Education Today. 2006;26:672-9.

5. Gitanjali B. Academic dishonesty in Indian medical colleges. J Postgrad Med. 2004;50:281-4.

6. Kenny D. Student plagiarism and professional practice. Nurse Education Today. 2006;27:14-8.

7. Elzubeir MA, Rizk DEE. Exploring perceptions and attitudes of senior medical students and interns to academic integrity. Medical Education. 2003;37:58996.

8. The fundamental values of academic integrity. Duke University: The Center for Academic Integrity, 1999.

9. Berman A, Snyder S, Kozier B, and Erbs G. Fundamental of nursing: concepts, process, and practice. $8^{\text {th }}$ ed. New Jersey: Prentice Hall, 2008.

10. Persatuan Perawat Nasional Indonesia. Kurikulum pendidikan sarjana keperawatan. Jakarta: AIPNI, 2008.

11. Thoha M. Perilaku organisasi: konsep dasar dan aplikasinya. Jakarta: Raja Grafindo Persada, 2008.

12. Sarwono SW. Teori-teori psikologi sosial. Edisi revisi. Jakarta: PT Raja Grafindo Persada, 2008.

13. Arhin AO. A pilot study of nursing student's perceptions of academic dishonesty: a generation y perspective. The ABNF Journal. 2009;17-21.

14. Grimes PW, Rezek JP. The determinants of cheating high school economics students: a comparative study of academic dishonesty in the transitional economies. International Review of Economic Education. 2005;4(2):23-45. 
15. Media Group. Mayoritas siswa-mahasiswa menyontek. Diunduh di: URL: http://manajemensekolah.teknodik. net/?p=965. Diakses 25 July 2009.

16. McCabe DL, Trevino LK, Butterfield KD. Honor code and other contextual influences on academic integrity: a replication and extention to modified honor code setting. Research in Higher Education. 2002;43(3):357-78.

17. McCabe DL, Trevino, Butterfield KD. Dishonesty in academic environments: the influence of peer reporting requirements. The Journal of Higher Education. 2001;72(1):29-45.
18. Rabi SM, Pharm D, Patton LR, Fjortoft N, Zgarrick DP. Characteristics, prevalence, attitudes, and perceptions of academic dishonesty among pharmacy students. American Journal of Pharmaceutical Education. 2006;70(4):8.

19. Hammer DP, Berger BA, Beardsley RS, Easton MR. Student professionalism. American Journal of Pharmaceutical Education. 2003; 67(3):1-28.

20. Potter PA, Perry AG. Fundamental of nursing: concept, process, and practice. $3^{\text {th }}$ ed. St. Louis: Mosby Year Book, 1993. 